\title{
Pesquisando Co-Viewing EM REDes Sociais E APLiCATIVos DE MENSAGEM INSTANTÂNEA: ÉTICA E DESAFIOS
}

\author{
Fernanda Pires de Sá
}

\begin{abstract}
RESUMO
Este artigo discute as preocupações e os desafios éticos que devem ser considerados durante o estudo da prática de covisualização (televisão social) dos conteúdos audivisuais nas mídias sociais e aplicativos de mensagens instantâneas. As práticas de covisualização se referem às atividades interconectadas que ocorrem enquanto os espectadores se sentam juntos em frente a um aparelho de TV, observando e construindo sentido a partir do conteúdo televisivo. Plataformas conectadas ampliam as possibilidades de covisualização, permitindo que as pessoas experimentem uma copresença digital. Neste estudo, os usuários que participaram em atividades de covisualização conectada em grupos não oficiais, do Facebook e do WhatsApp, dedicados à telenovela brasileira Babilônia (exibida em 2015), são usados para exemplificar a necessidade de estabelecer um consentimento informado ao realizar pesquisas online e evitar danos aos participantes. A pesquisa demonstra que uma tomada de decisão ética em relação aos dados e aos pontos de vista dos usuários estudados deve ser considerada e avaliada nos estágios iniciais e ao longo de cada etapa do estudo.
\end{abstract}

Palavras-chave

Consentimento informado; covisualização; estudo de caso; métodos digitais; plataformas conectadas

\begin{abstract}
This article discusses the ethical concerns and challenges that should be considered while studying the practice of co-viewing on social media and instant messaging applications. Coviewing practices refer to the intertwined activities that happen while viewers sit together in front of a TV set, watching and making meaning from television content. Connected platforms amplify the possibilities for co-viewing, by allowing people to experience a digital co-presence. Users that engaged in connected co-viewing in unofficial Facebook and WhatsApp groups dedicated to the brazilian telenovela Babilônia (airing in 2015) are used to exemplify the need to establish informed consent and avoid harming the participants when carrying out research online. The research reveals that ethical decision-making with respect to users' data and viewpoints had to be considered, not only at the beginning stages of research, but assessed and considered throughout each step of the study.
\end{abstract}

\section{KEYWORDS}

Case study; connected platforms; co-viewing; digital methods; informed consent 


\section{INTRODUÇÃo}

Pesquisar na internet e em plataformas conectadas se faz necessário, já que os meios ambientes digitais fazem parte do nosso cotidiano. Realizar pesquisas sobre esses espaços pode envolver tanto vantagens quanto desvantagens. Como muitos autores já apontaram, realizar pesquisas online pode ser menos custoso e consumir menos tempo do que a pesquisa em ambientes não digitais. No entanto, quando nos engajamos em uma pesquisa que envolve ou é feita através de plataformas conectadas, o design da pesquisa pode ser obrigado a passar por um processo de evolução contínua, uma vez que os espaços digitais estão sempre sendo alterados.

Este estudo de caso, realizado em dois grupos fechados do Facebook e um grupo do WhatsApp dedicado a covisualizar a telenovela brasileira Babilônia (que foi ao ar de março a agosto de 2015 na Rede Globo) evidencia a evolução no planejamento da pesquisa. O objetivo do estudo foi compreender como as práticas de covisualização (ver televisão conjuntamente) são reformuladas e moldadas tanto por plataformas digitais quanto pelas práticas e experiências dos usuários nesses espaços. Durante esta pesquisa, foi necessário adaptar continuamente o desenho metodológico devido aos dados empíricos encontrados no trabalho de campo, às questões impostas pelas interfaces onde a pesquisa ocorreu (Facebook e WhatsApp) e por contas das atividades de covisualização realizada pelos usuários. Embora os grupos estudados seguissem um gênero televisivo que tem uma base estável para o consumo, o fenômeno da covisualização conectada (também conhecido como televisão social) em sites de redes sociais e aplicativos de mensagens instantâneas era relativamente novo, portanto, tinha um grau de eventos inesperados. Isso se deve ao fenômeno estudado, que não fazia parte de um ambiente controlado. Os grupos do Facebook estavam em processo de formação e a telenovela vista pelos usuários substituiu uma telenovela anterior (telenovelas ficam em média seis meses no ar). Outro evento inesperado durante a pesquisa foi a formação de um grupo do WhatsApp dentro de um dos grupos do Facebook. Isso levou a investigar a covisualização também dentro desse espaço, o que gerou novas intuições e conhecimento.

A pesquisa, quando é feita online, pode envolver preocupações éticas significativas, especialmente para pesquisadores da vertente qualitativa, visto que o pesquisador deve ser sensível, pois o ambiente online pode afetar o contexto offline em que os participantes vivem e isso pode prejudicá-los (Eynon, Fry \& Schroeder, 2008). A internet também é um ambiente onde novos fenômenos e características técnicas são constantemente introduzidas e é necessário estar ciente dos riscos potenciais para os participantes. Por exemplo, observou-se que os usuários dos grupos estudados coletavam, compartilhavam e salvavam arquivos e links com o conteúdo da telenovela e sua trilha sonora sem as devidas permissões de direitos autorais. Algumas dessas atividades são ilegais e podem afetar a vida dos participantes.

A natureza mutável do problema de pesquisa demandou uma metodologia de estudo de caso que seguisse uma abordagem etnográfica. O objetivo geral do estudo exigiu o que Stake (2005) chamou de estudos de casos instrumentais, já que grupos particulares foram examinados, principalmente, para fornecer uma visão sobre uma questão, 
neste caso, uma visão sobre as práticas de covisualização conectada de um tipo de gênero televisivo - a telenovela do horário nobre brasileiro.

Conforme será demonstrado nas seções a seguir, os resultados desse projeto de pesquisa adaptativo e evolutivo são produtos de técnicas flexíveis para interagir com os participantes e trabalhar dentro do ambiente fluido das plataformas de redes sociais.

\section{CO-VIEWING E TELENOVELAS BRASILEIRAS EM ESPAÇOS CONECTADOS}

Os estudos de covisionamento originaram-se no campo da Psicologia na década de 1970 (Ball, Bogatz, Creech, Ellsworth \& Landes, 1970), quando os estudos começaram a reconhecer a importância de pares no momento de construir sentido, enquanto realizavam atividades de visualização televisiva.

Os estudos de covisualização, da mesma forma que os estudos culturais, deixaram para trás abordagens tradicionais que tendiam a ver o público como passivo ou simplesmente a não incluí-lo como tópico relevante para investigação. Desde o início, os estudos de covisionamento apontaram que assistir televisão sempre foi uma atividade social complexa, pois gera várias formas de engajamento social entre pares (McDonald, 1986). Antes do uso generalizado de dispositivos e de plataformas conectadas, o engajamento em torno da televisão era limitado ao aparelho de TV. Deste modo, o engajamento com a televisão tinha como característica a efemeridade, por não ser facilmente rastreável, já que as atividades do espectador se materializavam pessoal e físicamente.

Holt e Sanson (2014) denominaram o complexo contexto atual de mídias de visualização conectada, a qual "refere-se especificamente a uma experiência de entretenimento multiplataforma que se relaciona a uma tendência geral das indústrias de mídia que tentam integrar tecnologia digital e comunicação em redes sociais com práticas midiáticas massivas tradicionais" (Holt \& Sanson, 2014, p. 1). Covisionamento na era conectada pode acontecer de várias maneiras, ou seja, com pessoas fisicamente sozinhas, mas na companhia de outros pares online, ambas acompanhadas de pares offline e online ou da maneira tradicional, em que as pessoas se sentam e covisualizam juntas conteúdos audiovisuais. Além disso, a covisualização em plataformas conectadas pode deixar rastros no formato de dados, já que esses espaços digitais são baseados em conteúdo gerado pelo usuário. Agora, no entanto, a covisualização pode se materializar na frente de um aparelho de TV ou usando outros tipos de dispositivos de tela e redes sociais, que não estavam disponíveis nos primeiros anos da Internet.

Em ambos os ambientes, tradicionais e conectados, a covisualização permite a criação de significado ao compartilhar-se opiniões e interações durante a visualização. Deste modo, as características de um programa covisualizado desempenham um papel importante para que tais práticas ocorram. O tipo de conteúdo midiático que é covisualizado pode desencadear diferentes práticas relacionadas à geração de sentido, assim como à eleição do tipo de companhia que se pretende ter, ao visualizar dito conteúdo. $\mathrm{O}$ estudo de Dezfuli, Khalilbeigi, Mühlhuser e Geerts (2011), sobre as relações interpessoais em torno da TV, demonstrou que assim como na covisualização tradicional, presencial, 
os usuários que covisualizam online podem classificar seus círculos sociais para selecionar com quem desejam interagir. Isso depende do momento, da situação e do gênero do programa televisivo. Harris e Cook (2010) acrescentam que o prazer relacionado a um produto midiático pode ser mediado por diferentes preferências de gênero ou pela companhia que um televidente possa ter em uma dada situação. Isso pode levar uma pessoa a gostar muito do conteúdo ou a se sentir bastante angustiada em relação a ele. A presença de outras pessoas no momento do visionamento pode ser umas das razões.

O foco deste estudo se concentrou em um contexto local e específico de práticas de covisionamento dentro de grupos não oficiais do Facebook e WhatsApp relacionadas à telenovela do horário nobre brasileiro. Esse formato televisivo único é central para a observação de práticas de covisualização, pois inclui questões sociais e políticas em seu enredo, questões estas que vão além do aparelho de televisão (Atencio, 2014; Lopes, 2012; Pires de Sá, 2017; Pires de Sá \& Roig 2016). As telenovelas brasileiras foram consideradas durante décadas um ritual, através do qual as pessoas se reuniam diariamente ao redor da televisão para assiti-las. Com as redes sociais esse ritual está sofrendo um processo de transformação, já que passa a ser mais visível através do uso de diferentes tipos de materialidades digitais. A telenovela que foi covisualizada e serviu de base para este estudo chama-se Babilônia. Babilônia apresentou questões sociais muito delicadas, como homossexualidade feminina entre idosas, corrupção política, entre outros temas. O enredo polêmico de Babilônia levou a discussões na arena política e estabeleceu debates em múltiplos canais de mídia. Todos esses assuntos controversos fizeram parte das práticas de covisualização conectada. Neste estudo, foi possível ver como a covisualização conectada é uma prática que também se estende aos telespectadores da telenovela brasileira e, ao estudar esse fenômeno, pesquisadores precisam ter cuidado para não expor as atividades de covisualização online destas pesssoas e, portanto, evitar possíveis danos a elas.

\section{A SEleÇão da Plataforma do FACEBook}

O estudo foi inicialmente planejado para ser realizado em grupos do Facebook, especificamente em grupos dedicados à telenovela. Isso foi decidido após vários meses de observação dos grupos criados para acompanhar a telenovela Império (que foi ao ar de julho de 2014 a março de 2015) - antecessora da telenovela covisualizada neste estudo - e detectar o interesse dos usuários em novos grupos dedicados à Babilônia, antes mesmo de a telenovela ir ao ar. Essa decisão também foi inspirada por um estudo no Facebook desenvolvido por Lopes (2012), que preparou o terreno para investigar atividades relacionadas à telenovela dentro de grupos criados por usuários, em vez de estudar apenas espaços oficiais ou sancionados pela rede de televisão. De um modo geral, os trabalhos de Lopes proporcionaram uma perspectiva diferente aos estudos de recepção no Brasil e consolidaram a tradição de estudar telenovelas. A autora demonstrou que a telenovela faz parte da cultura brasileira e é um repertório compartilhado (Lopes, 2009), que representou o processo de industrialização do país (Lopes, 2000). A 
telenovela continua sendo um gênero de TV que ainda representa um ponto de encontro entre a cultura popular, a vida cotidiana, as questões sociais, a política e as indústrias de mídia. Lopes (2000), baseada na Teoria da Mediação de Martín-Barbero (1987) e na teoria de Múltiplas Mediações de Orozco (1993), implementou uma ferramenta teórico-analítica baseada no marco teórico das Mediações para superar as abordagens dominantes dos estudos de comunicação: a abordagem determinista baseada no modelo de Lasswell e de Shannon e, a abordagem da Escola de Frankfurt. A autora supera esses dualismos explorando, empiricamente, as formas multidimensionais de mediação no processo de recepção de uma telenovela. Os trabalhos de Lopes (2000) e Lopes, Borelli e Resende (2002) podem ser considerados inovadores, uma vez que exploraram as experiências de visionamento de quatro famílias de diferentes classes sociais. Os estudos observaram onde as mediações poderiam ocorrer, estabelecendo categorias de análise: cotidiano familiar, subjetividade, gênero e vídeo-técnica. Esta abordagem permitiu olhar para a recepção através de diferentes lentes, ressaltando o papel do poder e do discurso. Os trabalhos inovadores dessas pesquisadoras brasileiras validaram uma perspectiva metodológica multidisciplinar para estudar o processo de recepção da telenovela, usando diferentes técnicas qualitativas (não se limitando apenas à análise de conteúdo), e trouxeram o empirismo para o marco teórico latino-americano das mediações. Além disso, essa pesquisa de referência facilitou outros estudos por outros pesquisadores que utilizaram uma abordagem interdisciplinar e empírica para investigar o fenômeno da recepção. Portanto, pode considerar-se um passo à frente nos estudos brasileiros de recepção, particularmente na maneira de realizar um trabalho empírico de forma sistemática. Lopes (2014) também já havia indicado sobre a necessidade de se refletir a respeito da importância da tecnologia nos estudos de recepção e de ampliar o estatuto, tanto de teorias quanto de aspectos metodológicos das pesquisas no campo da comunicação. Com o objetivo de ampliar esse enfoque multidisciplinar e seguir a indicação da autora, estudei a covisualização em seu formato conectado. Esta pesquisa também teve como objetivo ampliar os poucos estudos recentes desenvolvidos pela equipe brasileira, liderada por Lopes, a qual faz parte do Observatório Ibero-Americano de Ficção Televisiva. Estes estudos buscaram compreender, sob o ponto de vista dos usuários, as atividades de visualização em plataformas conectadas, obras que são discutidas em um estudo relacionado (Pires de Sá, 2017).

A decisão de desenvolver este estudo usando o Facebook era atraente, porque o Facebook, na época, era a rede social mais utilizada no Brasil (Secretaria de Comunicação Social da Presidência da República, 2015). Por um lado, isso possibilitou observar como a prática de assistir televisão conjuntamente foi transferida e de algum modo transformada pelo uso de redes sociais e outras tecnologias de informação. Por outro lado, isso também foi uma decisão mais árdua, visto que o Facebook utiliza uma interface de programação de aplicativos (API, em inglês) que impõe diversas restrições para extrair dados. Uma API é:

(...) uma interface fornecida por um aplicativo que permite aos usuários interagir ou responder às solicitações de dados ou serviços de outro 
programa, outros aplicativos e sites. As API facilitam a troca de dados entre aplicativos, permitem a criação de novos aplicativos e formam a base para o conceito da 'Web como uma plataforma' ... programadores podem usar a técnica de raspagem de dados chamada screen scraping, uma técnica que extrai informação de qualquer tipo e de qualquer página na internet. (Murugesan, 2007, pp. 36-37)

Em comparação, o Twitter teria sido uma rede social mais fácil de estudar e pesquisar, já que a maioria dos dados desta rede social está disponível ao público, é facilmente recuperável, além de ser uma plataforma frequentemente utilizada por pesquisadores (Moe, Poell \&Van Dijck, 2016). No entanto, não oferece a possibilidade de analisar as atividades de covisionamento em grupo, da mesma maneira que o Facebook. Como eu pretendia realizar uma observação participante para entender melhor as práticas dos usuários, em vez de apenas revisar o conteúdo que eles produziam, esta investigação exigiu utilizar a metodologia de estudo de caso. Para isso, o consentimento informado dos usuários foi obtido e as diretrizes éticas recomendadas pelo Comitê de Trabalho de Ética da Associação de Pesquisadores da Internet (AOIR, seu acrônimo em inglês) foi seguido (Markham \& Buchanan, 2012).

\section{A METOdOLOgia do ESTUdo DE CASO}

A justificativa para a seleção do estudo de caso como metodologia aplicada tem origem no fenômeno que se decidiu estudar, no qual o contexto não podia ser controlado. Um estudo de caso possibilita observar uma questão através de diversos e variados ângulos e ajuda a alcançar uma compreensão mais equilibrada e profunda do objeto de pesquisa. Também é uma metodologia apropriada a se utilizar quando o pesquisador tem pouco ou nenhum controle sobre os eventos que estão sob investigação (Yin, 2003).

Flyvbjerg (2006) aponta que um estudo de caso fornece ao pesquisador uma proximidade das situações da vida real, portanto facilita a compreensão de um fenômeno social. Numerosas circunstâncias e pormenores surgem durante o processo de pesquisa e dependem do contexto onde ela é desenvolvida (Flyvbjerg, 2006), incluindo a tomada de decisões éticas. Isso significa que o estudo de caso produz um conhecimento experiencial, pois os objetos e participantes podem ser complexos e delimitados por seus contextos e circunstâncias do estudo (Stake, 2005; Thomas, 2015). Apesar de suas divergências relacionadas aos paradigmas científicos, Yin (2003), Stake (2005), Flyvbjerg (2006), Thomas (2015) e outros afirmam que um dos principais pontos fortes dessa metodologia é que ela permite o uso de várias fontes de informação e a aplicação de múltiplas técnicas para entender o objeto de estudo. Esta triangulação de métodos permite que o estudo de caso obtenha mais credibilidade, pois durante o período de estudo as descrições e interpretações não são feitas em um único momento. Em vez disso, decisões e passos são dados em várias etapas e momentos da pesquisa. Portanto, o estudo de caso leva o pesquisador a um processo de constante reflexão. 
Além disso, a triangulação de métodos permite uma melhor compreensão da situação em que o caso está inserido. Nos casos estudados nesta pesquisa, a metodologia e os vários métodos utilizados tiveram a influência da etnografia em termos tanto instrumentais, como relacionais. Os termos instrumentais dizem respeito aos métodos online que Kozinets $(2002,2010)$ chamou de "netnografia" (adaptada da etnografia). Estes métodos funcionaram como ferramentas de pesquisa para explorar grupos que existem em plataformas digitais como o Facebook e WhatsApp. Os termos relacionais auxiliaram a compreender as complexidades das atividades dos usuários, complexidades devidas à interconexão destas práticas.

Além do mais, ao utilizar a metodologia de estudo de caso, o pesquisador obtém um olhar mais atento às atividades do caso investigado e, também por isso, alcança uma proximidade maior e uma melhor compreensão do objeto estudado. Portanto, isso também permite que o pesquisador receba um feedback constante dos participantes do estudo (Flyvbjerg, 2006).

Ao utilizar a metodologia de estudo de caso, pude passar por esse processo de reavaliação, o que me permitiu observar se minhas proposições eram coerentes ou se deveriam ser melhor analisadas ou até revisadas. Como os casos estudados não seguiram o modelo dedutivo, e meu enfoque estava mais próximo do paradigma fenomenológico, foi possível acompanhar este processo de reavaliação ao longo das distintas fases do estudo e realizar as adaptações adequadamente. É importante ressaltar que comecei o estudo com ideias e objetivos preconcebidos que precisaram ser ajustados durante o processo de coleta de dados. Por exemplo, a hipótese de trabalho - de que os espaços não oficiais dentro de redes sociais são locais onde os usuários podem escapar da vigilânicia direta dos produtores televisivos e sentem-se à vontade para executar práticas de visualização que não aconteceriam em outros espaços ou situações - provou-se correta durante a pesquisa. No entanto, as expectativas iniciais de encontrar diversos usuários criando mashups, vídeos e memes como parte dessas atividades não foram completamente correspondidas. Os usuários não criavam este tipo de conteúdo, embora o compartilhassem durante a veiculação da telenovela. Ao dialogar com usuários em conversas informais e também durante as entrevistas, eles afirmaram criar conteúdo. Contudo, o modo como entendiam o que é produção de conteúdo era diferente da minha concepção inicial. O simples ato de opinar ou compartilhar qualquer conteúdo da telenovela era visto pelos usuários como um ato de produção de conteúdo. A descoberta de que a produção de conteúdo não precisava ser sofisticada, como é o caso dos mashups ou de vídeos, para ser uma produção de conteúdo, exigiu que eu adaptasse as perguntas e os objetivos de investigação.

Estas mudanças só puderam ser feitas pelo contato mais próximo que tive com os usuários, bem como com suas práticas e com o contexto onde ocorreram as práticas de covisualização. Assim, o estudo de caso me ajudou a entender melhor o fenômeno que estava sendo estudado e a contrastá-lo com concepções prévias.

Neste estudo, a triangulação de métodos foi utilizada, a fim de obter uma maior compreensão sobre os fenômenos de covisualização, e recorreu-se a: observação 
participante, entrevistas semi-estruturadas e um questionário qualitativo. Essa triangulação permitiu uma análise profunda das práticas de visualização dos grupos selecionados (dois grupos não oficiais do Facebook e um grupo do WhatsApp). A análise aprofundada foi possível graças à aplicabilidade às questões reais e contemporâneas que a metodologia do estudo de caso permite, quando se estuda um fenômeno em andamento, como é o caso da covisualização através de plataformas conectadas.

\section{SELEÇÃo dos CASOS ESTUdAdoS}

Como a covisualização acontece quando o conteúdo de mídia está sendo visualizado, uma das decisões metodológicas tomadas foi examinar as práticas ao mesmo tempo em que elas estavam acontecendo. Por isso, a telenovela selecionada para estudar a covisualização foi a Babilônia, já que, após o início do projeto, esta era a próxima telenovela a ir ao ar, no horário nobre da Rede Globo.

Por conta dos objetivos deste estudo, optei por focar a atenção nos grupos não oficiais do Facebook e nas atividades realizadas dentro deles, em vez de pesquisar espaços "oficiais" mediados pela rede de televisão, onde seria difícil ver práticas que poderiam ser consideradas ilegais, como a troca de arquivos. Além disso, o objetivo era observar as atividades das pessoas, e não uma idéia construída e predeterminada pelas instituições de uma audiência ou fã (Ang, 1991) ou moldada pelo canal de televisão. Eu também preferi me concentrar em espaços não oficiais, não por eles serem espaços mais representativos de registros das experiências de covisualização, mas porque são lugares ideais para observar e participar nas práticas de covisualização sem interferência ou vigilância possíveis da rede de televisão. Deve notar-se, no entanto, que esses grupos não eram espaços abertos ideais para o livre debate, pois havia formas de moderação e até censura por parte dos proprietários e administradores dos grupos, bem como pela filtragem de algoritmos que o Facebook utiliza para destacar algumas publicações (Araújo \& Pires de Sá, 2016), além de haver outras restrições diretas e indiretas impostas pelas plataformas (Pires de Sá, Araújo \& Roig, 2017).

Embora os grupos usassem plataformas que fazem parte de uma corporação privada como o Facebook, que também é dona do Whatsapp, os usuários percebiam que estes eram locais mais apropriados para desenvolver certas práticas. Por isso, foi possível observar as práticas de troca de arquivos e compartilhamento de conteúdo, debates sobre a função da telenovela, sobre suas características técnicas e sobre o modo como este gênero representa a realidade.

Os três grupos estudados foram selecionados de formas diferentes. No entanto, para esta pesquisa, segui a lógica dos casos coletivos instrumentais que foi definida por Stake (2005). Eu usei casos coletivos instrumentais para obter uma melhor compreensão do fenômeno de covisualização conectada. Stake (2005) difunde o uso de um estudo de caso instrumental quando "um caso particular é examinado principalmente para proporcionar informações sobre um assunto ou reformular uma generalização. O caso é de interesse secundário, desempenha um papel de apoio e facilita nossa compreensão 
de algo mais" (Stake, 2005, p. 445). Nesta pesquisa, eu estava interessada em entender as práticas de covisualização conectada e as de conteúdo gerado pelo usuário (CGU) relacionadas a um determinado tipo de programa de TV (a telenovela no horário nobre brasileiro). Para atingir esse objetivo, os grupos de Babilônia foram estudados em profundidade, seguindo a afirmação de Stake (2005) de que ainda que o caso seja de interesse secundário, "o caso é analisado em profundidade, os contextos são analisados e as atividades ordinárias são descritas detalhadamente, mas tudo isso é feito porque nos ajuda a alcançar um interesse externo" (Stake, 2005, p. 445).

Vários grupos do Facebook dedicados a seguir Babilônia foram criados antes mesmo de Babilônia começar a ir ao ar. Estes grupos começaram a se formar mais de um mês antes do final da telenovela anterior (Império). Isso ocorreu quando a Rede Globo começou a divulgar a sinopse e exibiu alguns teasers durante os intervalos de sua programação. Dentro dos grupos existentes de Império, criadores e administradores dos novos grupos de Babilônia convidaram os usuários a participar, o que assegurou que haveria grupos para estudar as práticas de covisualização e as de CGU relacionadas a este gênero de televisão. Um mês antes da data de lançamento da Babilônia (seu primeiro episódio foi ao ar no dia 16 de março de 2015) existiam cerca de 10 grupos ativos.

Para selecionar os casos dentro desta população de grupos de Babilônia, a lógica da amostragem intencional foi aplicada ao selecionar os dois grupos mais ativos, levando-se em consideração os grupos nos quais as pessoas postavam e comentavam com mais frequência. Isso foi feito porque em grupos onde houvesse menos interações, possivelmente, não ocorreriam atividades de covisualização da mesma forma que em grupos ativos. Como Rubin e Babbie (2016) apontam, a amostragem intencional é uma técnica na qual os casos são escolhidos a dedo por terem certos atributos ou por realizarem práticas representativas a um grupo específico que seja relevante para o estudo. Portando, a amostragem intencional foi baseada na intenção de participar em espaços onde as práticas de covisualização fossem se materializar devido à atividade dos usuários participantes. $O$ grupo do WhatsApp, por outro lado, não foi selecionado intencionalmente. Em um dos grupos estudados, foi criado um subgrupo do Whatsapp, no qual os usuários eram convidados a participar, deixando o seu número de telefone em um comentário. Como era do meu próprio interesse observar a covisualização de forma conectada, também forneci meu número de telefone. Em vista disso, a seleção do grupo do WhatsApp se enquadra ao tipo de amostragem em bola de neve que é frequentemente empregada para tentar "obter informações e acessar 'populações ocultas'” (Noy, 2008, p. 330).

\section{CONSENTIMENTO INFORMADO E PREOCUPAÇÕES ÉTICAS}

Esta pesquisa foi realizada dentro das micro-ecologias do Facebook (dois grupos não oficiais e fechados) e WhatsApp (um grupo), duas plataformas que estão sempre adicionando ou alterando seus recursos. São espaços digitais que podem ter áreas nebulosas no momento de ter que realizar uma tomada de decisão ética. A fim de superar estas áreas nebulosas durante o processo de investigação, as diretrizes sugeridas pela AOIR foram seguidas. Estas diretrizes indicam que uma abordagem indutiva é uma das 
maneiras mais adequadas de evitar danos aos participantes da pesquisa e superar sua possível vulnerabilidade (Markham \& Buchanan, 2012).

Neste estudo, a abordagem indutiva foi baseada em vários aspectos, mas sempre foi considerado que o dano aos participantes pode ser determinado contextualmente. Por esta razão, as decisões éticas foram tomadas de acordo com cada situação apresentada durante o processo de investigação, ao invés de serem realizadas de maneira universal (Markham \& Buchanan, 2012; Nissenbaum, 2010). No WhatsApp, por exemplo, os usuários são obrigados a expor o seu número de telefone para poder usar os serviços e conectar-se com os seus pares. Isto pode ser percebido pelos usuários como um canal muito particular de comunicação. No Facebook, os usuários precisam registrar seus metadados (nome, sexo etc.) para ter acesso aos serviços. Em ambos os casos, a percepção de privacidade não é absolutamente evidente. Ao contrário, como já mencionado por Nissenbaum (2010), as expectativas dos participantes e o consenso sobre o que se entende por privacidade desempenham um papel importante em pesquisas na internet. Pesquisadores não devem ignorar a percepção de privacidade dos participantes, especialmente nos casos em que os usuários podem não estar cientes das configurações de privacidade e de dados, conforme fora levantado durante este estudo. Os usuários de plataformas digitais realizam muitas atividades online por dia e, no entanto, não sabem muito sobre os regulamentos de dados (Madejski, Johnson \& Bellovin, 2011). Ao conversar com os participantes sobre este tema, muitos afirmaram apenas pressionar o botão e concordar sem ler os termos e condições e os acordos de licença de utilização que, geralmente, são exibidos ao criar um perfil nas redes sociais ou ao atualizar aplicativos.

Isso significa que, dependendo das circunstâncias, os resultados da pesquisa podem indignar os participantes (Reilly \& Trevisan, 2016), por isso, os pesquisadores devem ir além da adesão à definição de privacidade dada pela plataforma. De tal modo que o consentimento informado deva ser sempre uma questão a ser lembrada antes de se iniciar uma pesquisa em plataformas conectadas, pois os contextos online e offline estão geralmente interligados. Logo, durante as diferentes fases desta pesquisa, observou-se que qualquer tomada de decisão em espaços digitais envolve dados que podem revelar informações pessoais e delicadas de indivíduos (Markham \& Buchanan, 2012) e, em alguns casos, causar-lhes ansiedade (Pink, Lanzeni \& Horst, 2018).

Existem debates sobre o facto de o Facebook ser ou não ser um espaço público. Seguindo esses debates, Reilly e Trevisan (2016) analisaram os Termos e Condições e, com base nas configurações de privacidade, salientaram que o Facebook pode ser um espaço público e privado ou até mesmo um espaço semi-público. No caso de espaços digitais como os grupos do Facebook, as configurações são públicas, fechadas ou secretas. Os grupos estudados tinham o status de fechado, no qual apenas os membros podem postar e ver os posts um do outro. Portanto, os grupos estudados foram considerados espaços semi-públicos e o consentimento informado era uma questão importante que foi levada em conta.

Após selecionar os estudos de caso e antes de iniciar o processo de coleta de dados, uma página foi criada no Facebook. Isso foi feito para fornecer informações sobre 
as diferentes etapas e notícias relacionadas ao projeto de pesquisa, bem como para informar aos possíveis participantes sobre os objetivos gerais do estudo e atuar como um canal aberto para a comunicação. Além disso, como assinala Hine (2008), é importante que os pesquisadores online tenham páginas informativas na web para que os informantes possam verificar a identidade e as afiliações dos pesquisadores e legitimá-los como acadêmicos, quando realizarem um estudo de etnografia virtual. Por essa razão, incluí nesta página do Facebook, uma ligação que direcionava ao site da universidade à qual sou afiliada. Esta ligação incluía uma descrição do meu grupo de pesquisa e seus membros.

A escolha do Facebook como plataforma de hospedagem desta página foi baseada na ideia de que os usuários estudados estariam utilizando a mesma rede social que usam normalmente para acessar os grupos, agilizando dessa forma o acesso à página, já que eles estariam conectados ao Facebook.

Esta página também foi uma ferramenta que ajudou a obter o consentimento informado dos proprietários dos grupos, administradores e dos usuários estudados. Isso possibilitou deixar claro os objetivos do estudo e explicar aos participantes que sua colaboração era voluntária e não obrigatória (Estadella \& Ardevol, 2007; Hine, 2008; Miller \& Boulton, 2007).

Primeiramente, os proprietários e administradores do grupo foram contatados através do meu perfil pessoal do Facebook para receber informações pertinentes sobre a forma como eu pretendia desenvolver este projeto de pesquisa. A decisão de usar o meu perfil real do Facebook enquanto participava dos grupos, ou conversava com os usuários, foi tomada com a intenção de transmitir confiança. Consequentemente, isso possibilitou a criação de laços sólidos com os usuários enquanto participava nas práticas dos grupos, pois eles viam a pesquisadora como uma pessoa real. A página do Facebook foi fundamental para estabelecer esse contato e apresentar o estudo.

Em segundo lugar, após entrar em acordo com proprietários e administradores dos grupos, várias postagens foram feitas dentro dos mesmos para engajar os participantes. Essas postagens explicavam que eu participaria nos grupos, ao mesmo tempo que estudaria as atividades dos usuários e reuniria seus dados. Sempre que necessário, resolvia as dúvidas dos usuários, por meio de comentários e durante conversas realizadas pelo Facebook Messenger ou WhatsApp. Os usuários também foram encorajados a falar abertamente caso não quisessem que suas informações fossem utilizadas, algo que ocorreu com dois participantes.

Lidar com as preocupações em relação ao anonimato dos dados também ajudou a obter o consentimento informado. Foi declarado explicitamente aos informantes que suas informações pessoais não seriam reveladas. Isso foi dito e reiterado durante conversas informais com usuários, entrevistas, na apresentação do questionário e em publicações. Embora tenha usado o nome real da telenovela que eles estavam covizualizando, ao expor os resultados da pesquisa (apresentações e publicações) nunca usei os nomes reais dos grupos, nem forneci ligações para as suas postagens. Além disso, ambos os grupos tiveram seus nomes alterados em diversas ocasiões, impossibilitando o reconhecimento dos grupos estudados, ainda mais com o grande fluxo de informações que tiveram. 


\section{DESAFIOS AO ESTUdAR A COVISUALIZAÇÃO EM UM CONTEXTO CONECTADO: A NECESSIDADE DE MOVER-SE ENTRE A COLETA E A ANÁLISE DE DADOS}

Como observadora participante, era crucial covisualizar a telenovela junto com os membros do grupo. Ao realizar as atividades com os usuários, foi possível compreender como as práticas de covisionamento eram realizadas e quais eram suas motivações. Geralmente estavam relacionadas às características da interface e suas restrições. Por exemplo, o grupo do WhatsApp tinha muito menos usuários do que os grupos do Facebook e, ainda assim, a atividade era muito maior. Isso pode ser atribuído à interface do WhatsApp, que é um aplicativo de mensagens instantâneas que permite que as mesmas sejam entregues e acessadas rapidamente pelo smartphone. Já no Facebook, é necessário estar conectado a esta rede social para ver as mensagens dentro dos grupos de interesse. Além disso, enquanto eu participava na covisualização era possível discutir os tópicos e as atividades dos grupos, bem como compará-los com os conjuntos de dados extraídos. Essa comparação, feita com os conjuntos de dados extraídos durante a observação participante, foi essencial, pois seguiu a lógica de que os dados de covisualização, como outros dados digitais, vão além da ideia de um arquivo. Essas atividades foram vistas como práticas humanas dinâmicas, em tempo real, que ocorrem em espaços digitais (Kitchin, 2014; Pink et al., 2018). Se eu não tivesse feito parte dos grupos e não participasse nas atividades de covisualização, seria quase impossível ler ou ter uma compreensão mais profunda do conteúdo e dos dados gerados durante as atividades de pré-visualização, covisualização e pós-visualização da telenovela. Portanto, o processo de estudar a covisualização em plataformas conectadas baseou-se num movimento entre a coleta de dados e a análise de dados, ou seja, sucedeu por meio de um processo de constante evolução e adaptabilidade.

Durante o primeiro mês de exibição de Babilônia, após covisualizar a telenovela dentro dos grupos estudados, o plugin N Capture do NVIVO 10 foi usado para extrair os conjuntos de dados de cada dia do Facebook e, assim, poder comparar com as notas de campo e experiências vividas.

Todos os dias, usei os recursos de codificação do NVIVO para estabelecer e armazenar dados relevantes em categorias e conceitos por meio dos chamados "nós". A realização desta atividade diária foi necessária, por causa do alto volume de dados que era produzido. Durante a covisualização, parecia que a quantidade de dados era menor do que em momentos em que realizava a análise de dados. Isto porque eu estava vendo e participando nas atividades que estavam acontecendo quase de forma sincronizada. No entanto, quando analisava os conjuntos de dados notava que a quantidade era realmente maior, já que cada postagem ou comentário representava uma linha no conjunto de dados do NVIVO; até mesmo quando eram apenas emoticons ou palavras soltas. Por exemplo, durante o primeiro episódio, o conjunto de dados continha novecentas e quarenta e duas linhas (incluindo postagens e comentários) de ambos os grupos do Facebook. Portanto, exigiu um processo constante de seleção e categorização do conteúdo relevante. Essa seleção foi baseada na minha experiência de covisualização e nas anotações feitas durante essa prática. 
A mudança da API do Facebook, no final de abril de 2015, impossibilitou a mineração de dados dos grupos do Facebook. Por isso, foi necessário proceder-se a uma adaptação da coleta de dados. A solução encontrada foi criar uma planilha no Excel com as atividades mais relevantes. Essa relevância foi baseada nos tópicos e no engajamento dos usuários. Normalmente, cada interação salva tinha pelo menos dez ou mais comentários. Essa decisão diminuiu a quantidade de dados que eu precisava armazenar e alterou o processo de codificação. Na planilha, incluí minhas anotações, ligações e salvei o rastro de toda a interação entre os usuários em uma das linhas. As planilhas de Excel foram importadas para o NVIVO e codificadas uma vez por semana. No grupo do WhatsApp, fiz anotações das atividades e no final do trabalho de campo baixei um arquivo de texto e o importei para o NVIVO.

As entrevistas também foram efetuadas e acessadas para realizar uma análise inicial durante o período de coleta de dados; isso foi uma forma de dialogar com as práticas de visualização dos usuários. Codifiquei (categorizei) as entrevistas de duas maneiras diferentes. A primeira maneira consistiu em criar nós para cada pergunta, para vizualizar juntas as respostas de todos os entrevistados. Na segunda maneira, inclui informações relevantes nos nós já criados durante a observação participante.

O questionário foi elaborado com base nas entrevistas e nas práticas de covisualização observadas. Foi desenvolvido com o Formulário do Google e disponibilizado durante a última semana de exibição da telenovela. O NVIVO foi usado para executar consultas e testes. Esses testes e consultas também foram aplicados aos dados da observação participante e das entrevistas. Como, por exemplo, procurar as palavras mais utilizadas para contrastar com as categorias existentes, para visualizar uma palavra em um contexto particular e assim por diante.

No início, o processo de classificação da análise era intuitivo e um grande número de nós foi criado. Após algumas semanas de transmissão da telenovela, padrões começaram a emergir e os nós começaram a adquirir uma forma mais definida, o que consequentemente diminuiu o número de nós durante o processo de análise. Após o término do trabalho de campo, os dados codificados foram posteriormente analisados, e propriedades comuns e padrões de práticas sociais foram encontrados entre os nós.

\section{CONCLUSÕES}

Este artigo demonstra que os casos estudados me levaram a aprender na prática, pois algumas das minhas intuições e concepções iniciais foram alteradas durante o trabalho de campo. Isso se deve ao fato da covisualização conectada ser uma prática que está viva, ou seja, está sempre evoluindo. A covisualização conectada depende do gênero visualizado, dos covisualizadores, dos locais onde ocorre, da tecnologia e da materialidade disponível para a realização desse tipo de atividade. Verificou-se que as interfaces das plataformas (Facebook e WhatsApp) nas quais a pesquisa foi desenvolvida estão sempre evoluindo e possuem características capazes de moldar a experiência de covisualização conectada. Portanto, estudar um fenômeno "vivo" como a covisualização 
conectada, no contexto de redes sociais e de aplicativos de mensagens instantâneas, provou ser possível somente com o uso de uma metodologia flexível que considere a tomada de decisão ética de forma contextual em todas as etapas da pesquisa e que permita ao pesquisador mover-se constantemente entre a coleta e a análise de dados.

Os aspectos metodológicos do estudo, suas etapas e as decisões éticas tomadas durante a pesquisa foram importantes porque contribuíram para o campo relativamente recente de investigação sobre as atividades dos usuários, nas plataformas de rede sociais, nos estudos de recepção e mais particularmente nos estudos de telenovela. A abordagem metodológica utilizada neste estudo seguiu um procedimento ético indutivo, para proceder à observação participante e coletar dados de redes sociais com o consentimento informado dos usuários. Isso abriu espaço para debater a importância do tratamento ético ao estudar sujeitos que utilizam redes sociais e aplicativos de mensagens instantâneas na realização de atividades de visionamento. Foi demonstrada também a necessidade de se abordar o problema de pesquisa conscientemente e de forma explicita, já que a maneira como os dados são tratados pode afetar o cotidiano dos usuários, em questões como privacidade de dados, temas sociais discutidos, atividades ilícitas, entre outros aspectos. A tomada de decisão ética fez parte deste processo de pesquisa adaptativa, porque os usuários seguiam uma telenovela que estava em desenvolvimento. Isso confirma que a realização de pesquisas éticas no ambiente conectado requer que o pesquisador tome decisões sensíveis durante todo o processo, já que não é possível controlar o ambiente da pesquisa.

Convém destacar os procedimentos de consentimento informado que foram realizados ao participar nas atividades dos usuários e durante toda a pesquisa. Se eu não tivesse seguido essas diretrizes metodológicas e não tivesse me envolvido nas práticas dos grupos estudados, teria tido apenas uma compreensão superficial das práticas de covisualização conectada que ocorriam nos espaços estudados e nas atividades relacionadas com elas. Ou seja, eu teria mantido minha posição e concepções iniciais. Os espaços oficiais podem ser convenientes para os pesquisadores investigarem os hábitos de visualização. No entanto, deve-se enfatizar que a maioria dessas práticas só puderam ser estudadas porque ocorreram dentro de um espaço não estabelecido pelos produtores. Este estudo indica que às vezes a seleção de espaços não oficiais para observação pode ser frutífera, pois pode propiciar a descoberta de práticas que nunca seriam vistas em espaços oficiais. Além disso, o Facebook e o WhatsApp revelaram-se como plataformas frequentemente utilizadas para realizar o acompanhamento de atividades de TV ao vivo.

Os aspectos procedimentais e contextuais do processo de pesquisa podem ter limitado as descobertas e contribuições deste estudo. No entanto, eles também criaram oportunidades para uma melhor compreensão da trajetória, do lugar e do contexto onde o estudo ocorreu. Como fora explicado, uma das restrições deste estudo foi a mudança da API da plataforma do Facebook que impediu a mineração de conjuntos de dados de grupos fechados. Isso exigiu que eu salvasse manualmente os dados para a análise futura. No entanto, essa limitação também foi uma oportunidade para desenvolver uma compreensão mais profunda do ambiente material e digital no qual as práticas 
de covisualização conectada ocorreram. Foi possível entender como o Facebook, redes sociais e aplicativos de mensagens instantâneas fazem parte de um ciclo de constante atualização. Isso afeta os procedimentos de pesquisa, exigindo que os pesquisadores sejam flexíveis e revisem continuamente seus processos de investigação.

Os grupos cresceram ao longo dos meses do estudo. Devido ao grande número de membros nos grupos do Facebook e muitos usuários no grupo do WhatsApp, não foi possível conhecer todos os participantes envolvidos nas práticas estudadas ou ter certeza absoluta de que todos os participantes estavam cientes do estudo. Diante do vasto número de pessoas e de informações, essa foi uma oportunidade para entender que a tomada de decisão ética e o consentimento informado provêm da postura e das decisões que o pesquisador toma, de acordo com o contexto encontrado. Para isso, o pesquisador precisa esforçar-se para proteger e evitar danos aos participantes, olhando o conteúdo das redes sociais como parte e propriedade dessas pessoas e não como meros textos.

Em pesquisas futuras se almeja ampliar os temas e métodos explorados neste estudo. A abordagem da pesquisa e os métodos aplicados devem ser explorados em contextos semelhantes e em diversas formas de visualização. Por exemplo, seria interessante pesquisar covisualização em outros gêneros de televisão ou em outras formas de visualização que não estejam marcadas pelo horário de transmissão.

Em conclusão, este estudo empregou desenvolvimentos fundamentais em aspectos metodológicos para realizar um estudo de caso sobre um fenômeno vivo, como é o caso da covisualização em mídias sociais e aplicativos de mensagens instantâneas, utilizando uma abordagem qualitativa que seguiu os protocolos éticos de consentimento informado. As contribuições originais e significativas deste estudo continuarão a ser exploradas para melhor entendimento de nossa crescente socialibilidade conectada.

Traduzido por Fernanda Pires de Sá

\section{REFERÊNCIAS BIBLIOGRÁFICAS}

Ang, I. (1991). Desperately seeking the audience. Londres: Routledge.

Araújo, W. \& Pires de Sá, F. (2016) Facebook's algorithms and its opaque design of transparency: how followers of the most popular Brazilian TV show perceive their news feed. In T. Martínez \& J. L. Marzo (Eds.), Interface politics (pp. 6og-623). Barcelona: GREDITS.

Atencio, R. (2014). Memory's turn: reckoning with dictatorship in Brazil. Madison: University of Wisconsin Pres.

Ball, S., Bogatz, G.A., Creech, R., Ellsworth, R. \& Landes, S. (1970). The First year of sesame street: an evaluation. Final report.Retirado de http://files.eric.ed.gov/full- text/EDo47823.pdf

Dezfuli, N., Khalilbeigi, M., Mühlhuser, M. \& Geerts, D. (2011). A study on interpersonal relationships for social interactive television. In Proceedings from EurolTV '11: The ninth international interactive conference on interactive television (pp. 21-24). Nova lorque: ACM.

Estalella, A. \& Ardèvol, E. (2007). Ética de campo: hacia una ética situada para la investigación etnográfica de internet. Forum Qualitative Social Research, 8(3), 1-25. doi: 10.17169/fqs-8.3.277 
Eynon, R., Fry, J. \& Schroeder, R. (2008). The ethics of internet research. In J. Hughes (Ed.), Sage internet research methods (pp. 23-41). Londres: Sage.

Flyvbjerg, B. (2006). Five misunderstandings about case-study research. Qualitative Inquiry, 12(2), 219-245. doi: $10.1177 / 1077800405284363$

Harris, R. J. \& Cook, L. (2010). How content and co-viewers elicit emotional discomfort in moviegoing experiences: where does the discomfort come from and how is it handled? Applied Cognitive Psychology, 25(6),850-861. doi: 10.1002/acp.1758

Hine, C. ( 2008). Virtual ethnography: modes, varieties, affordances. In N. Fielding, R. M. Lee \& G. Blank (Eds.), The Sage handbook of online research methods (pp. 257-270) Los Angeles: Sage.

Holt, J. \& Sanson, K. (2014). Introduction. In J. Holt \& K. Sanson (Eds.), Connected viewing: selling, streaming, Q sharing media in the digital era (pp. 1-17). Nova lorque e Londres: Routledge.

Kitchin, R. (2014). The data revolution. Londres: Sage.

Kozinets, R. V. (2002). The field behind the screen: using netnography for marketing research in online communities. Journal of Marketing Research, 39(1), 61-72. doi: 10.1509/jmkr.39.1.61.18935

Kozinets, R. V. (2010). Netnography: doing ethnographic research online. Londres: Sage.

Lopes, M. I. V. (2000). Metodologia para o estudo da recepção de telenovelas no Brasil. Comunicação $e$ Sociedade, 14(1-2), 93-112. doi: 10.17231/comsoc.2(2000).1386

Lopes, M. I. V., Borelli, S. H. S. \& Resende, V. R.(2002). Vivendo com a telenovela: mediações, recepção, teleficcionalidade. São Paulo: Summus Editorial.

Lopes, M. I. V. (2009) Telenovelas as a communicative resource. Matrizes 3(1), 1-23. doi: 10.11606/issn.1982816o.v3i1р21-47

Lopes, M. I. V. (2012). A case study on transmedia reception: fandom on facebook and social issues in the Brazilian telenovela Passione. Anàlisi: Quaderns De Comunicació i Cultura (Vol Especial), 111-132.

Lopes, M. I. V. (2014). Mediação e recepção. Algumas conexões teóricas e metodológicas nos estudos latinoamericanos de comunicação. Matrizes, 8(1), 65-80. doi: 10.11606/issn.1982-8160.v8i1p65-80

Madejski, M., Johnson, M. \& Bellovin, S.M. (2011). The failure of online social network privacy settings. Department of Computer Science, Columbia University, Tech. Rep. CUCS-010-11, 1-20. Retirado de https://fpf.org/wp-content/uploads/2011/07/The Failure of Online Social Network Privacy Settings.pdf

Martín-Barbero, J. (1987). De los medios a las mediaciones: comunicación, cultura y hegemonía. Barcelona: Ediciones G. Gili.

McDonald, D.G. (1986) Generational aspects of television coviewing. Journal of Broadcasting Q Electronic Media 30(1), 75-85. doi: 10.1080/08838158609386609

Markham, A., Buchanan, E. \& AolR Ethics Working Committee. (2012). Ethical decision making and internet research - version 2.o. Retirado de http://www.dphu.org/uploads/attachements/books/books_5612_o. pdf

Moe, H., Poell, T. \& van Dijck, J. (2016). Rearticulating audience engagement social media and television. Television a New Media, 17(2), 99-107. doi: 10.1177/1527476415616194

Murugesan, S. (2007). Understanding Web 2.0. IT professional, 9(4), 34-41. doi: 10.1109/MITP.2007.78 
Miller, T. \& Boulton, M. (2007). Changing constructions of informed consent: qualitative research and complex social worlds. Social Science Q Medicine, 65(11), 2199-2211. doi:10.1016/j. socscimed.2007.08.009

Nissenbaum, H. (2010). Privacy in context: technology, policy, and the integrity of social life. Stanford: Stanford University Press.

Noy, C. (2008). Sampling knowledge: the hermeneutics of snowball sampling in qualitative research. International Journal of Social Research Methodology, 11(4), 327-344. doi: 10.1080/13645570701401305

Orozco, G. G. (1993). Dialéctica de la mediación televisiva. Estructuración de estrategias de recepción por los televidentes. Anàlisi: Quaderns de Comunicació i Cultura, 15, 31-44.

Pink, S., Lanzeni, D. \& Horst, H. (2018). Data anxieties: finding trust in everyday digital mess. Big Data Q Society, January-June, 1-14. doi: 10.1177/2053951718756685

Pires de Sá, F. \& Roig, A. (2016). Challenging prime time television: co-viewing practices in the Brazilian telenovela. Convergence: The International Journal of Research into New Media Technologies, 22(4), 392407. doi: $10.1177 / 1354856516641623$

Pires de Sá, F. (2017). Connected co-viewing on Facebook: a Brazilian telenovela and the perception of media realism. Television and New Media, 1-14. doi: 10.1177/1527476417741672

Pires de Sá, F., Araújo, W. \& Roig, A. (2017). Narrativa de los usuarios: los usos de plataformas y tecnologías digitales en nuestras prácticas creativas cotidianas. Rizoma, 5(2), 8-16. doi: 10.17058/rzm.v5i2.11528

Reilly, P. \& Trevisan, F. (2016). Researching protest on Facebook: developing an ethical stance for the study of Northern Irish flag protest pages. Information, Communication Q Society, 19(3), 419-435. doi. $10.1080 / 1369118 X .2015 .1104373$

Rubin, A. \& Babbie, E. R. (2016). Empowerment series: research methods for social work. Boston: Cengage Learning.

Secretaria de Comunicação Social da Presidência da República (2015). Pesquisa Brasileira de Mídia. 2015. Hábitos de Consumo de Mídia pela População Brasileira. Retirado de http://www.secom.gov. $\mathrm{br/atuacao/pesquisa/lista-de-pesquisas-quantitativas-e-qualitativas-de-contratos-atuais/pesquisa-}$ brasileira-de-midia-pbm-2015.pdf/

Stake, R. E. (2005). Qualitative case studies. In N. K. Denzin \& Y. S. Lincoln (Eds.), The Sage handbook of qualitative research (pp. 443-466). Thousand Oaks: Sage.

Thomas, G. (2015). How to do your case study. Londres, Thousand Oaks, Nova Delhi, Singapura: Sage.

Yin, R. K. (2003). Case study research: design and methods. Thousand Oaks, CA: Sage.

\section{Nota BiográFicA}

Fernanda Pires de Sá é pesquisadora de pós-doutorado no grupo de pesquisa Mediaccions: Cultura Digital da Universitat Oberta de Catalunya. É doutora em Sociedade da Informação e o Conhecimento pela mesma instituição. Seus interesses principais de investigação incluem métodos digitais, métodos qualitativos, covisualização, práticas sociais, cultura popular, e materialidades digitais.

E-mail: fpires@uoc.edu 
Morada: Universitat Oberta de Catalunya

Avinguda del Tibidabo, 39, 08035 Barcelona, Espanha

* Submetido: 30.11 .2017

* Aceite: 15.03 .2018 